ORIGINAL ARTICLE

\title{
Population based epidemiology of ankle sprains attending accident and emergency units in the West Midlands of England, and a survey of UK practice for severe ankle sprains
}

\author{
S A Bridgman, D Clement, A Downing, G Walley, I Phair, N Maffulli
}

Emerg Med J 2003;20:508-510

See end of article for authors' affiliations

Correspondence to:

Dr S A Bridgman, Keele

University, School of

Medicine, Postgraduate

Medicine, Hartshill Road,

Stoke on Trent ST4 7QB,

UK; stephen.bridgman@

newcastle-ul-pct.nhs.uk

Accepted for publication 2 February 2003

\begin{abstract}
Objectives: To estimate the incidence of ankle sprains and severe ankle sprains attending accident and emergency (A\&E) units; to describe current practice for severe ankle sprains in A\&E units in the United Kingdom.

Methods: Crude age and sex specific incidence rates were calculated for four health districts from cases ascertained from data on seven A\&E clinical information systems. Case records of patients with ankle sprains at an A\&E unit in another health district were audited and the proportion of severe ankle sprains calculated. UK A\&E units were surveyed about their usual treatment of patients with severe ankle sprains. Results: The estimate of the crude incidence rate of ankle sprains was a minimum of 52.7 per 10000 , rising to $60.9(95 \% \mathrm{Cl} 59.4$ to 62.4$)$ when figures were adjusted for the proportion of patients without a diagnostic code (13.7\%). There were important age-sex differences with unadjusted rates observed from 127.8 per $10000(\mathrm{Cl} 115.5$ to 140.0$)$ in girls aged $10-14$ years to $8.2(\mathrm{Cl} 4.2$ to 12.3$)$ in men aged $70-$ 74 years. As $14 \%$ of ankle sprains attending A\&E were classed as severe, this would equate to 42000 severe ankle sprains per year in the UK. In the UK wide survey, there was a response rate of $79 \%(211$ of 266 ). Among the responders, Tubigrip was used routinely in 55\%, below knee casts in $3 \%$, and braces in $2 \%$. Boots were not used routinely in any unit.

Conclusion: While there is considerable variation in severe ankle sprain management in UK A\&E units, most are treated with the minimal mechanical support of Tubigrip.
\end{abstract}

$\mathrm{S}$ evere ankle sprains are associated with both short and long term disability. ${ }^{1}$ Their management is controversial. ${ }^{1}$ Acute surgical repair of damaged ligaments has been advocated, but overall there is little good evidence that it is cost effective. ${ }^{2}$ Casts can be useful to enable patients to return to activities more quickly, but may have the disadvantages of muscle atrophy and joint stiffness. There is some evidence that casts may be less effective than functional treatments, but the trials are generally small and of limited quality. ${ }^{1}$ Protected immobilisation with a brace or boot may offer the best of both worlds. ${ }^{3}$ Walking boots mechanically restrict ankle and subtalar joint motion, while permitting the boot to be removed at rest for a range of motion and dynamic exercises. Braces mechanically restrict inversion and eversion movements at the subtalar joint, while permitting free plantar and dorsiflexion. It has been argued that even the minimalist NHS approach of a double layer of tubular bandage is a waste of considerable resources. ${ }^{4}$

To investigate existing evidence on the epidemiology of severe ankle sprains, and variations in management, we searched Medline from 1970 using the terms 1. "Sprains and Strains"; 2. Ankle injuries; 3.1 and 2; 4. (ankle\$1 adj4 sprain\$).tw; 5.(ankle\$1 adj4 strain\$).tw; 6. (ankle\$1 adj4 inver\$).tw; 7. (ankle adj4 ligament\$ adj4 injur\$).tw; 8.or/4-7; 9.3 or $8 ; 10$. limit 9 to human. We also searched the Cochrane Controlled Trials Register, and the bibliographies of the articles we obtained. Studies describing incidence from particular populations, population based studies, are necessary to provide comparisons of the relative frequency of injuries between different areas. We found one population based study, from a county in Denmark with a population of
$110000 .^{5}$ Holmer et $a l^{5}$ reported a crude incidence rate of ankle sprains attending the emergency department of 70 per 10000 people per year. We found no studies on variations in management of severe ankle sprains.

The objectives of this study are: to estimate the incidence in four health districts of ankle sprains and severe ankle sprains attending accident and emergency (A\&E) units; to estimate the number of ankle sprains and severe ankle sprains seen at A\&E units in the United Kingdom (UK); and to describe current practice for severe ankle sprains in A\&E units in the UK.

\section{METHODS}

Firstly, we undertook a population based study on four adjacent urban West Midlands health districts. They have a combined population of about 1.1 million people. The districts were: Dudley (305 000 people), Sandwell (290 000 people), Walsall (260 000 people), and Wolverhampton (242 000 people) (Office of National Statistics 1998 population estimates). ${ }^{6}$ This population is largely served by four A\&E units located within each district. Datasets are supplied routinely from these units to the West Midlands A\&E Surveillance Centre at the University of Birmingham and stored in an Access database. Cases included were defined as a first attendance at A\&E between April 2000 and March 2001, and having a diagnostic code of ankle sprain. Incidence rates were calculated as the number of ankle sprains in residents of these four districts, divided by the resident population using the most recently available Office of National Statistics population estimates (1998). ${ }^{6}$ The 95\% confidence intervals were also calculated. ${ }^{7}$ Some A\&E records 
did not have the diagnostic code field filled in. To adjust for this, it was assumed that the proportion of ankle sprains in those patients without a diagnostic code was the same as in those in whom a diagnostic code was recorded.

Secondly, we undertook a prospective audit of patients with ankle sprains attending the A\&E unit at the North Staffordshire Hospital NHS Trust in May, August, November 2001, and February 2002. These four months are equally spaced throughout the year, and we assume they are representative of the year. This hospital was chosen as background data were required for a proposed randomised controlled trial, it was the base hospital of the study team, and resources were identified to undertake the work. We did not have the resources to collect data in every month, therefore months were chosen to be spaced evenly throughout the year. Data recorded by attending clinical staff on routine A\&E casualty records was extracted by a research nurse or clinical auditor on a daily basis, except cases that presented at the weekend, which were reviewed on the following Monday. Severe ankle sprains were defined as those in which it was recorded that patients were non-weight bearing on first attendance, had lateral ankle tenderness, and did not have a fracture if radiographed. Cases that did not meet these criteria were excluded. A\&E clinical staff in North Staffordshire are trained in the Ottawa decision rules definition for non-weight bearing, namely unable to weight bear immediately after injury and unable to walk four steps in the A\&E department. ${ }^{8}$

Thirdly, we researched current practice for severe ankle sprains in the UK. A questionnaire was developed and piloted locally. It was then posted to the clinical directors/heads of department of the 266 A\&E units in the UK. Those who had not responded after the first posting were sent a postal reminder, and then received a telephone reminder. Units not responding after this were considered non-responders. We did not request information on the person filling in the questionnaire, although in some cases this was given. A copy of the questionnaire used is available on the journal web site (http://www.emjonline.com/supplemental).

\section{RESULTS}

\section{Population based incidence}

We recorded 5776 new cases of ankle sprain in residents of Dudley, Sandwell, Walsall, and Wolverhampton health districts. A total of 5761 (99.7\%) of these were recorded from one of the four local hospitals. The crude incidence rate of recorded ankle sprains in the four West Midlands health districts from April 2000 to March 2001 was a minimum 52.7 per 10000 (95\% confidence intervals (CI) 51.3 to 54.0).

At the four hospitals above, the data completeness for diagnosis was $88 \%, 100 \%, 89 \%$, and $68 \%$ respectively. Of A\&E records at these hospitals $86.3 \%$ (241 644 of 280 107) had a diagnostic code, and $13.7 \%$ (38 452 of 280 107) did not. When the number is adjusted for records at these hospitals without a diagnostic code, it is calculated to be 6678 , a rate of 60.9 (CI 59.4 to 62.4) per 10000 persons. If the adjusted rate of 60.9 per 10000 is applied to the England and Wales populations (using the 1998 UK population estimates, ${ }^{6}$ the most recently available) the estimated number of sprains is 302000

There were marked age-sex differences. Observed unadjusted rates varied from 127.8 per 10000 (CI 115.5 to 140.0) in girls $10-14$ years to 8.2 per 10000 (CI 4.2 to 12.3 ) in men aged $70-74$ years (fig 1 , table 1 ).

\section{Audit at North Staffordshire Hospital}

Ankle sprains were the diagnosis recorded in $2.77 \%$ ( 1115 of 40 308) of new attenders at North Staffordshire Hospital NHS Trust A\&E department. Of these, 14\% were classed as

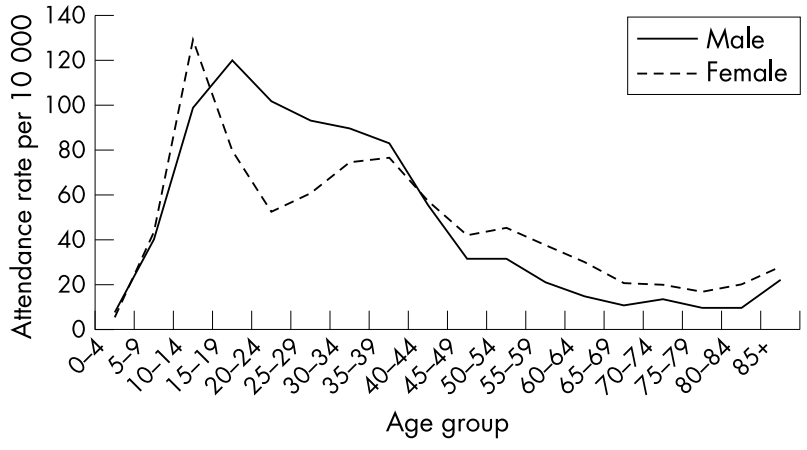

Figure 1 Age-sex specific rates of ankle sprain attendance at A\&E units in residents for four West Midlands health districts (1 April 2000 to 31 March 2001).

severe $(0.32 \%$ of all new attenders $)$. If the proportion of severe sprains at North Staffordshire Hospital were reflected nationally then the estimated number of severe ankle sprains in the UK $(302000 \times 0.14)$ would be 42000 .

\section{Current management survey}

Our survey of current management of severe ankle sprains produced a response rate of $79 \%$ (211 of 266). Tubigrip was used to some extent in 175 of $211(83 \%)$ units, below knee casts in $114(54 \%)$, braces in $36(17 \%)$, and boots in $10(5 \%)$. Fifty five per cent (117 of 211 ) of units used Tubigrip for more than $75 \%$ of cases, $3 \%$ (7) below knee casts, $2 \%$ (5) braces, $0 \%(0)$ boots.

It is assumed that the information recorded and supplied to the A\&E Surveillance Centre is accurate. The data supplied by North Staffordshire Hospital to the A\&E Surveillance Centre could not be used to cross check data from the second study with the routine data used in the first study, given the completeness of diagnostic coding. There is no reason to doubt that the proportion of severe sprains seen in North Staffordshire is similar to those in other A\&E units, and that the proportion of ankle sprains in patients without a diagnostic code is the same as that in those with one.

\section{DISCUSSION}

This study is the first we are aware of in the United Kingdom to try to quantify the incidence of ankle sprains and severe ankle sprains attending A\&E departments for a geographical population. Based on our study, we estimate 302000 new ankle sprains and 42000 new severe ankle sprain patients attend A\&E departments in the UK every year. Our survey of current UK practice for severe ankle sprains illustrates the wide variation in current practice, but that most ankle sprains are treated with the minimal mechanical support of Tubigrip.

Estimates of the total number of ankle sprains are restricted to injuries seen in A\&E units. These will underestimate the true incidence rate in the general population, because a proportion of patients with ankle sprains may not seek health advice or will have been seen in an alternative healthcare setting, such as primary care. It would be expected, however, that the vast majority of patients with severe ankle sprains will be seen in an A\&E unit. An unknown, but probably very small proportion of cases, will not have been ascertained because they were seen either at units outside the West Midlands, or in West Midlands units from where we do not have data.

One of the limitations of using routinely collected A\&E data is that there are currently no standard data quality checks in place. Those performed are hospital specific, and are primarily designed to check that codes are valid rather 
Table 1 Numbers and rates of ankle sprain attenders in residents of four West Midlands health districts, April 2000 to March 2001 , by age (years) and sex

\begin{tabular}{|c|c|c|c|c|c|c|c|c|c|}
\hline Age band & Male & Population & Rate & Female & Population & Rate & All attenders & Population & Rate \\
\hline $0-4$ & 29 & 38341 & 7.56 & 18 & 36407 & 4.94 & 47 & 74748 & 6.29 \\
\hline $5-9$ & 135 & 35963 & 37.54 & 161 & 34600 & 46.53 & 296 & 70563 & 41.95 \\
\hline $10-14$ & 346 & 34087 & 101.50 & 410 & 32088 & 127.77 & 756 & 66175 & 114.24 \\
\hline $15-19$ & 457 & 38010 & 120.23 & 279 & 36041 & 77.41 & 736 & 74051 & 99.39 \\
\hline $20-24$ & 438 & 43546 & 100.58 & 229 & 44063 & 51.97 & 667 & 87609 & 76.13 \\
\hline $25-29$ & 394 & 41905 & 94.02 & 257 & 42861 & 59.96 & 651 & 84766 & 76.80 \\
\hline $30-34$ & 336 & 37503 & 89.59 & 278 & 37211 & 74.71 & 614 & 74714 & 82.18 \\
\hline $35-39$ & 287 & 34637 & 82.86 & 257 & 33749 & 76.15 & 544 & 68386 & 79.55 \\
\hline $40-44$ & 202 & 37072 & 54.49 & 204 & 36228 & 56.31 & 406 & 73300 & 55.39 \\
\hline $45-49$ & 104 & 34054 & 30.54 & 136 & 33257 & 40.89 & 240 & 67311 & 35.66 \\
\hline $50-54$ & 97 & 32230 & 30.10 & 142 & 31525 & 45.04 & 239 & 63755 & 37.49 \\
\hline $55-59$ & 60 & 30096 & 19.94 & 112 & 29997 & 37.34 & 172 & 60093 & 28.62 \\
\hline $60-64$ & 45 & 29718 & 15.14 & 90 & 30610 & 29.40 & 135 & 60328 & 22.38 \\
\hline $65-69$ & 27 & 26368 & 10.24 & 58 & 29961 & 19.36 & 85 & 56329 & 15.09 \\
\hline $70-74$ & 16 & 19418 & 8.24 & 51 & 25838 & 19.74 & 67 & 45256 & 14.80 \\
\hline 75-79 & 17 & 13081 & 13.00 & 34 & 21137 & 16.09 & 51 & 34218 & 14.90 \\
\hline $80-84$ & 6 & 6821 & 8.80 & 29 & 14461 & 20.05 & 35 & 21282 & 16.45 \\
\hline $85+$ & 7 & 3264 & 21.45 & 28 & 10305 & 27.17 & 35 & 13569 & 25.79 \\
\hline All ages & 3003 & 536114 & 56.01 & 2773 & 560339 & 49.49 & 5776 & 1096453 & 52.68 \\
\hline
\end{tabular}

than correct. The only way of investigating the accuracy of the codes would be to manually check against the paper records, and this is outside the scope of this study. The authors are unaware of any published studies that have investigated the quality of A\&E data. In the field of A\&E, there is relatively little information available. The standard dataset of A\&E information supplied to the West Midlands A\&E Surveillance Centre is a readily available data source, containing the basic information needed for analysis. Although we are making an assumption that the data are correct, we believe that this is justified through the validation checks performed by the hospitals and a lack of any other routinely collected information.

Our incidence rates for ankle sprain cases attending A\&E of 60.9 per 10000 were slightly lower than those in the only other population based study we are aware of, the 70 (95\% CI 65 to 75 ) per 10000 reported by Holmer et al, in Denmark.

While Tubigrip is the predominant support given in the UK, there was considerable variation in practice. Devices such as boots or braces may become more popular in the UK. The unit costs of devices and the labour to fit them is estimated to be, per each patient, $£ 60$ for boots (Bledsoe), $£ 30$ for braces (Aircast), $£ 12$ for below knee plaster casts, and $£ 2$ for Tubigrip (from retailers list prices, estimates of nurse time to fit devices in a pilot study, and standard NHS nursing costs at North Staffordshire Hospital NHS Trust A\&E unit). These are approximate estimates, and wide variations in price may exist between countries both in device and labour charges. Also, there is a large number of different devices available. If all severe ankle sprains in the UK were treated by one method only, this would equate to $£ 3$ million for boots, $£ 1.5$ million for braces, £0.6 million for below knee plaster, and $£ 0.1$ million for Tubigrip per year. This is a hypothetical illustration of costs, but illustrates the possible financial implications of practice change on the UK National Health Service.

There is some evidence that interventions that immobilise the ankle, such as below knee plaster, are less effective than those which permit early movement. ${ }^{1}$ Given the absence of commercial necessity to undertake trials of devices for the management of ankle sprains, the paucity of high quality trials in this field, ${ }^{1}$ and the wide range of costs of different treatments, evidence is needed to identify the most cost effective strategy of managing such a common problem.

\section{ACKNOWLEDGEMENTS}

Ms Rachel Raybould, clinical auditor, assisted with the conduct and analysis of the ankle sprain audit at North Staffordshire Hospital. Dr Richard Wilson advised on the West Midlands ankle sprain epidemiology analysis.

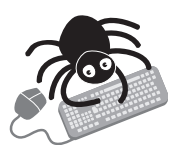

A copy of the questionnaire used in the study is available on the journal web site (http://www. emjonline.com/supplemental).

\section{Authors' affiliations}

S A Bridgman, D Clement, G Walley, N Maffulli, School of Medicine, Keele University, Stoke on Trent, UK

A Downing, Shool of Medicine, Birminham University, UK I Phair, Department of Accident and Emergency, North Stafffordshire Hospital NHS Trust, UK

Funding: this research was funded by the North Staffordshire Health Authority, North Staffordshire Hospital NHS Trust, Newcastle-underLyme Primary Care NHS Trust, West Midlands National Health Service Executive, West Midlands Health Authorities.

Conflicts of interest: none declared.

\section{REFERENCES}

1 Kerkhoffs GMMJ, Rowe BH, Assendelff WJ, et al. Immobilisation for acute ankle sprain: a systematic review. Arch Orthop Trauma Surg $2001 ; 121: 462-71$.

2 Punenburg ACM, Van Dijk CN, Bossuyt PMM, et al. Treatment of ruptures of the lateral ankle ligaments: a meta-analysis. J Bone Joint Surg 2000;82A:761-73.

3 Richie DH Jr. Treating ankle sprains with applied biomechanics: understanding a complex physiological structure for optimum treatment. Podiatry Management 2001;20:129-48.

4 Wilson S, Cooke M. Double bandaging of sprained ankles. BMJ 1998:317:1722-3.

5 Holmer P, Sondergaard L, Konradsen L, et al. Epidemiology of sprains in the lateral ankle and foot. Foot Ankle Int 1994;15:72-4.

6 Office for National Statistics. Estimated mid-year resident population-England and Wales. London: ONS, 1998.

7 Gardner MJ, Altman DG. Statistics with confidence. London: BMJ Publishing, 1989.

8 Stiell iG, McDowell I, Nair RC. Use of radiography in acute ankle injuries: physician's attitudes and practice. Can Med Assoc J 1992;147:1671-8. 